\title{
Increased Proteasomal Degradation of Bax is a Common Feature of Poor Prognosis Chronic Lymphocytic Leukemia
}

Samir G. Agrawal ${ }^{1,2,3 *}$, Feng-Ting Liu ${ }^{1}$, Catherine Wiseman², Sima Shirali", Hongxiang Liu“, Debra Lillington ${ }^{4}$, Ming-Qing Du", Denise Syndercombe-Court ${ }^{1}$, Adrian C Newland ${ }^{1,2}$, John G. Gribben ${ }^{3,5}$ and Li Jia ${ }^{1}$

Institutions: ${ }^{1}$ Centre for Haematology, Institute of Cell and Molecular Science; ${ }^{2}$ Dept. of Haematology, ${ }^{3}$ Dept of Haemato-Oncology, ${ }^{4}$ Cytogenetics and ${ }^{5}$ Institute of Cancer, CRUK, Queen Mary University of London and Barts and the London NHS Trust; "Division of Molecular Histopathology, Department of Pathology, University of Cambridge, UK.

Address correspondence to:

Dr S. Agrawal, Stem Cell Laboratory, Haematology, St Bartholomew’s Hospital, West Smithfield, London, EC1A 7BE. T: +44 - 207601 8202; F: +44-207 601 8200; email: s.g.agrawal@qmul.ac.uk

Running title: Bax instability is a poor prognostic marker in CLL

*: SGA and FTL contributed equally to this work.

This work was supported by grants from the Research Advisory Board of St Bartholomew's and the Royal London Charitable Foundation, the Leukemia \& Lymphoma Society, USA and Leukaemia Research Fund, UK. 


\begin{abstract}
Many biological markers are associated with poor prognosis in chronic lymphocytic leukemia (CLL), but their mechanistic role remains unclear. Bax is an essential proapoptotic protein and decreased levels in malignant cells lead to resistance to apoptosis. Using a Bax degradation activity (BDA) assay, CLL cells were found to show variable Bax instability. However, BDA did not correlate with Bax protein levels: BDA positive and negative cases had high and low baseline Bax levels. BDA positive cases showed a marked accumulation of poor prognostic markers - unmutated immunoglobulin heavy chain variable genes, ZAP-70/CD38 positivity, 11q22/17p13 deletion, and short lymphocyte doubling time. Patients with BDA positive cells had a shorter median overall survival (OS) (126 months v. not reached, $\mathrm{p}=0.011)$ and time to first treatment $(16 \mathrm{v}$. 156 months, $\mathrm{p}=0.029$ ) than BDA negative cases. Dual BDA and ZAP-70 positivity had a median OS of 84 months $(\mathrm{p}=0.012)$. The BDA assay measures the intrinsic ubiquitin/proteasome activity of CLL cells and dynamic changes in Bax protein levels over time. Mechanistically, Bax instability may represent a final common pathway for disparate prognostic markers, as well as being itself an indicator of poor prognosis.
\end{abstract}

Key words: CLL; Bax; ZAP-70; CD38; Ig VH; cytogenetics. 


\section{Introduction}

The clinical course of B-cell chronic lymphocytic leukemia (CLL) is highly heterogeneous. Disease progression and survival correlate not only with clinical parameters, but also with a plethora of biological prognostic markers, including immunoglobulin (Ig) heavy chain variable gene (VH) mutation status, ${ }^{1,2}$ ZAP-70, ${ }^{3-5}$ CD38 expression. ${ }^{1}$ Recurrent cytogenetic abnormalities, with loss of the short arm of chromosome 17 (17p deletion), confer a very poor prognosis ${ }^{6}$ with the presumed mechanism of action involving (at least) loss of p53. Furthermore, functional loss of p53 activity, even in cases without a detectable p53 mutation, has been suggested as one mechanism underlying the poor prognosis associated with unmutated Ig VH genes. ${ }^{7}$ The molecular mechanisms underlying the worse prognosis in CLL with unmutated Ig VH, ZAP-70 or CD38 expression also remain elusive, although enhanced cell signaling/survival have been implicated. ${ }^{8-10}$ The role of ZAP-70 in enhancing signaling has been questioned in recent work showing that B-cell receptor triggering was not influenced by the ZAP-70 status of CLL cells. ${ }^{11}$ Clearly, further work is required to elucidate the cellular and molecular mechanisms that underlie the observed clinical value of these prognostic markers.

Fundamental to all malignant cells is the property of uncontrolled cell growth, often combined with resistance to apoptosis - a characteristic feature of CLL cells. A key pro-apoptotic protein is Bax, with low levels of, or absent, Bax expression in malignant cells being associated with resistance to treatment. Several pro-apoptotic molecules have been shown to be regulated by the ubiquitin/proteasome pathway, including $\mathrm{p} 53,{ }^{12} \mathrm{Bid},{ }^{13}$ Bax, ${ }^{14,15}$ ARTS $^{16}$ and NOXA. ${ }^{17}$ Furthermore, Bax instability was found in malignant cells 
and cell lines, ${ }^{15,18}$ as well as primary CLL cells. ${ }^{19}$ In the accompanying paper (Liu et al,), we investigated Bax degradation activity in cell lines, its role in TNF-related apoptosis inducing ligand (TRAIL)-induced apoptosis of CLL cells and its modulation by proteasome inhibition. Bax degradation in cell lines was found to be located in mitochondria, as opposed to the cytosol, and required an active ubiquitin/proteasome machinery. Bax instability was a mechanism of resistance to TRAIL-induced apoptosis, with proteasome inhibitors overcoming this resistance by stabilizing Bax and preventing degradation of ubiquitinated Bax. These findings suggested that testing for Bax instability in CLL may help guide therapeutic choices, with marked Bax degradation activity indicating that combined TRAIL and proteasome inhibition could be useful in some patients. This paper further investigates the utility of measuring Bax instability in CLL. We looked at a cohort of patients with CLL and compared Bax degradation activity with established prognostic markers: Ig VH mutation status, ZAP-70, CD38, cytogenetics, as well as clinical stage and lymphocyte doubling time (LDT). 


\section{Materials and Methods}

\section{Cell culture and clinical samples}

The protocol was approved by our local Ethical Committee. The diagnosis of CLL was made by standard criteria: cellular morphology and immunophenotyping (CD5+, CD19+, CD23+, weak surface Ig staining and weak CD79b with FMC7 negativity). All cases had a significant lymphocytosis of $>40 \times 10^{9} / \mathrm{L}$. Peripheral blood was obtained after written informed consent from patients with CLL. Patients had either never received treatment for their CLL or were at least 6 months post their previous course of treatment. Mononuclear cells were isolated by density centrifugation over Ficoll. Cells were cultured in RPMI-1640 medium (Sigma) supplemented with 10\% heat-inactivated fetal calf serum (FCS), $25 \mathrm{mM}$ HEPES, $2.0 \mathrm{mM}$ L-glutamine, $\mathrm{pH} 7.4$, at $37^{\circ} \mathrm{C}$ in a $5 \% \mathrm{CO}_{2}$ humidified incubator.

\section{Prognostic markers in CLL: ZAP-70 and CD38 by flow cytometry}

ZAP-70 and CD38 by flow cytometry are routinely available as part of the diagnostic work-up for all CLL cases in our immunophenotyping laboratory. Briefly, direct staining of whole blood with conjugated anti-CD38-PE, clone T16, (Beckman Coulter, Villepinte, France) and anti-CD19-FITC, clone J4.119 (Beckman Coulter) was performed, followed by red cell lysis using the Beckman-Coulter ImmunoPreP reagent system and samples were read on a Coulter XL4-MCL flow cytometer. CD38 positivity was set at a threshold of $>20 \%$. Intracellular staining for ZAP-70 involved: initial surface marking with antiCD3-PE (UCHT1) (Beckman Coulter) and CD56-PE (N901[NKH-1]) (Beckman Coulter), permeabilization with Dako Intrastain (Dako, Cambridgeshire, U.K.) and 
labeling with anti-ZAP-70, clone 2F3.2, (Upstate-Millipore) followed by a goat-antimouse pan IgG (H+L) FITC (Southern Biotechnology, Alabama, U.S.A.). CLL ZAP-70 expression was assessed by gating out CD3 and CD56 positive cells. Positivity was set at a threshold of $>20 \%$.

\section{Prognostic markers in CLL: Analysis of somatic mutation of the rearranged immunoglobulin heavy chain (IgVH) genes}

DNA was extracted from peripheral blood leukemia cells - in some cases from fixed, stained slides - using QIAamp DNA Blood Mini kit (Qiagen, Crawley, West Sussex, U.K.) and subjected to PCR of the rearranged immunoglobulin heavy chain gene from the framework 1 to the joining region using the BIOMED-2 multiplex PCR protocols (InVivoScribe Technologies, LLC, San Diego, CA, USA). PCR products were analyzed by polyacrylamide gel electrophoresis and clonal PCR products were purified using QIAquick PCR purification kits (QIAGEN), followed by direct sequencing twice with the consensus primer to the joining region on an ABI 377 DNA sequencer. In cases where direct sequencing failed, PCR products were cloned and at least four clones were sequenced using vector primers. The consensus sequence in each case was subjected to database search for identification of the variable (V), diversity (D) and joining (J) germline segments used and somatic mutation in the rearranged $\mathrm{V}$ segment using DNAPLOT and VBASE2 (http://www.vbase2.org/).

\section{Prognostic markers in CLL: cytogenetic analyses}

Interphase FISH analysis was performed using the commercially available Vysis CLL probes (Abbott Diagnostics) to detect the common CLL associated abnormalities; deletions of ATM (11q23), D13S319 (13q14) and p53 (17p13), trisomy 12 using a 
chromosome 12 centromere probe (CEP12). FISH was also set up to exclude the presence of the $\mathrm{t}(11 ; 14), \mathrm{ICH} / \mathrm{CCND} 1$ associated with mantle cell lymphoma. The probes were applied as dual colour probe pair sets (ATM/p53, D13S319/CEP12 and IGH/CCND1) and used according to the manufacturers protocol. For each probe set, 100 interphases were scored on Leica DMXRA microscope fitted with a COHU CCD camera using MacProbe V4.1.1 CGH software (PSI/Applied Imaging).

\section{In vitro Bax degradation assay}

CLL cells were incubated in the Buffer A (250 mM sucrose, $10 \mathrm{mM}$ HEPES-KOH, pH 7.4, $10 \mathrm{mM} \mathrm{KCl,} 1 \mathrm{mM}$ EDTA, $1 \mathrm{mM}$ EGTA, $1 \mathrm{mM}$ DTT, $0.1 \mathrm{mM}$ PMSF, protease inhibitor cocktail 1:100, $50 \mu \mathrm{g} / \mathrm{ml}$ creatine phosphokinase, $10 \mathrm{mM}$ phosphocreatine, 2 mM ATP, and $0.1 \%$ Triton X-100) for 20 minutes on ice. Cells were then broken with a glass Dounce homogenizer (Jencons, Leighton Buzzard, U.K.) and nuclei removed by spinning at $790 \times g$ for 10 minutes at $4^{\circ} \mathrm{C}$. The post-nuclear supernatant was used as the cellular extract for the Bax degradation activity (BDA) assay. After the addition of 2 $\mu \mathrm{g} / \mathrm{ml}$ ubiquitin (Sigma, Dorset, U.K.), the protein extract in $5 \mathrm{mg} / \mathrm{ml}$ concentration was incubated at $37^{\circ} \mathrm{C}$ for up to 5 hours in the Buffer $\mathrm{A}$ in the presence of the ATP regeneration system and protease inhibitor cocktail. Proteins were taken out hourly and Bax levels determined using Western blotting and subsequent measurement of band density. BDA was calculated as the ratio of Bax level at three hours in the assay,

compared with its level at time 0. Samples with less than 20\% Bax degradation (BDA $>0.8$ ) were considered BDA negative. 


\section{Western blotting}

In order to assess Bax expression, CLL cells were placed in lysis buffer (1\% Triton X100, $0.5 \%$ sodium deoxycholate, $0.1 \mathrm{SDS}, 1 \mathrm{mM}$ PMFS, $10 \mu \mathrm{g} / \mathrm{ml}$ aprotinin, $10 \mu \mathrm{g} / \mathrm{ml}$ leupeptin, $1 \mathrm{mM}$ sodium orthovanadate, $1 \mathrm{mM}$ DTT in PBS, $\mathrm{pH}$ 7.4). Proteins were subjected to standard SDS-PAGE at 20-40mA/gel and transferred on to PVDF membrane at $100 \mathrm{~V}$ for 1 hour. PVDF membrane was blocked with $1 \%$ non-fat milk in PBST for 1 hour and probed for various proteins using the monoclonal anti-Bax 2D2 antibody, clone YTH-2D2 (R \& D Systems, Oxon, U.K.) or the monoclonal anti- anti- $\beta$-actin antibody (Sigma). Bound antibodies were detected using HRP-conjugated anti-mouse antibody (Santa Cruz, U.S.A) followed by detection using SuperSignal West Pico Chemiluminescent Substrate (Perbio Science UK Ltd. Northumberland, U.K.). The density of each band was analyzed using an AlphaImager ${ }^{\mathrm{TM}} 2000$ Densitometer (Alpha Innotech Corp. San Jose, CA).

\section{Statistical analysis}

Binary comparisons between Bax degradation activity (positive or negative) were made with Binet stage (A or not $\mathrm{A}$ ), presence of $\operatorname{IgV}_{\mathrm{H}}$ mutation, ZAP-70 and CD38 positivity, LDT (>12 months or other), karyotype (11q- or 17p- / other) using Chi-square with Yate's correction or 2-sided Fisher's Exact test, as appropriate. Survival time and time to treatment between Bax groups was compared using Kaplan-Meier plots and Cox’s F test. Multivariate analysis was undertaken using a generalized non-linear binomial model using logit analysis. Statistical significance was assumed at a p-value of $<0.05$. 


\section{Results}

\section{Bax instability in CLL cells}

In the accompanying paper, Bax protein levels were found to vary with individual malignant B-cell lines. This variation was not related to Bax mRNA expression, suggesting regulation at the post-translational level (Liu et al,). A specific defect of Bax stability was found in malignant B-cells and BDA was higher in these than in control tissues. In this paper, the work has been extended to 40 cases of CLL. In these patients, Bax degradation was positive (active) in 26 out of 40 cases, but negative in normal peripheral blood lymphocytes (Figure 1). The level of Bax instability varied and is shown schematically as ' + ' to ' +++ ' in Figure 1. No degradation in Bak, Bcl-2, Bcl-XL was detected in CLL cells. NOXA and PUMA proteins were not expressed in unstimulated CLL cells (results not shown).

\section{Bax degradation activity does not correlate with Bax protein levels}

It was important to establish whether the differential responses in the BDA assay were related to the baseline level of Bax protein in CLL cells. Bax protein expression was tested in 15 CLL samples - 8 BDA positive and 7 BDA negative. Figure 2 shows that there was no correlation between BDA and Bax protein levels, with BDA positive and negative cases having both high and low levels of basal Bax.

\section{Bax degradation activity is associated with poor prognostic markers in CLL}

The instability of Bax protein in CLL cells, as indicated by the BDA assay, could represent a new prognostic marker with biological relevance. Therefore, we looked at the correlation of BDA with established prognostic markers. The characteristics of the cohort 
of 40 cases of CLL are shown in Table 1. Overall, 27\% (11/40) of cases were Binet stage B/C at diagnosis, while 48\% (19/40) had a LDT $<12$ months (including cases requiring therapy before the LDT could be established). In terms of biological parameters, $45 \%$ (13/29) of cases had unmutated Ig VH, 38\% (15/39) were ZAP-70 positive, 45\% (18/40) CD38 positive and 15\% (6/40) had 11q22 or 17p13 deletions. In our diagnostic practice, with a population of nearly 2 million, ZAP-70 and CD38 positivity are typically seen in one third of cases (data not shown). Thus, this cohort of patients with CLL appears to represent a higher risk population than the general CLL population, which is in keeping with the bias of a tertiary referral center, as recognized in the literature.,5

The identification of two populations of CLL cases - those in whom the cells had stable Bax and those that showed Bax instability - led us to investigate the distribution of various prognostic markers in the two groups. The 26 cases showing Bax degradation activity (BDA positive) had a marked accumulation of poor prognostic features (Table 2): 10/11 of the Binet stage B/C patients, 9/13 Ig VH unmutated cases, 12/15 of the ZAP70+, 15/18 of the CD38+, 15/19 of the LDT $<12$ months patients, and all of the six 11q22 or $17 \mathrm{p} 13$ deletion cases. However, probably because of a lack of power, individually, none of these apparent associations with BDA positivity were statistically significant (Table 2),

\section{Bax degradation activity is associated with poor outcomes in CLL}

Median OS in the BDA positive group was 126 months, which was significantly worse than in the BDA negative group ( $\mathrm{p}=0.011)$ (Figure 3 ); and the median time to treatment was 16 months compared to 156 months for the BDA negative group (Figure 4) $(\mathrm{p}=$ 0.029). The median OS and time to treatment for $\mathrm{VH}$ mutation, ZAP-70 and CD38 are 
also shown in Figures 3 and 4, respectively. The only combination of parameters which improved prognostication were: BDA+ / ZAP-70+ (84 months, $\mathrm{p}=0.012)$; BDA+ / Binet stage $\mathrm{B} / \mathrm{C}$ and CD38+ (31 months, $\mathrm{p}=0.001$ ) (Figure 4). Similarly, with respect to time to first treatment, BDA positivity was as useful as the other biological parameters, (Figure 3) and no combination of BDA+ with unmutated VH, ZAP-70+ or CD38+ improved the prognostic value. As Binet stage B/C and LDT $<12$ months are themselves criteria for instituting therapy for CLL, these parameters confound the interpretation of time to treatment analyses. Multivariate analysis with BDA, VH status, ZAP-70, CD38 and caryotype, looking at survival, only identified unmutated $\mathrm{VH}$ as being significant ( $\mathrm{p}$ $=0.005)$. With respect to time to first treatment, no parameter was found to be significant in multivariate analysis. 


\section{Discussion}

B-CLL is characterized by long-lived cells in vivo, high levels of anti-apoptotic Bcl-2 and remains an incurable disease requiring repeated treatments. Pro- and anti-apoptotic members of the Bcl-2 family of proteins play a key role in the balance between cell death and survival. Low levels, or absence, of the pro-apoptotic molecule, Bax, have been associated with resistance to apoptosis in a variety of malignant B-cells. ${ }^{18-20}$ Bax degradation activity, or loss of Bax protein expression, is associated with poor prognosis in prostate cancer and melanoma. ${ }^{15,21}$ In CLL, low Bax levels (mRNA and/or protein expression) have been associated with a poor prognosis, ${ }^{22-25}$ but this has not been confirmed in other studies. ${ }^{26,27}$ The present study has looked at Bax protein instability measured using the BDA assay. Bax instability was more common in poor prognosis CLL and patients with BDA positive cells had a worse prognosis, with a shorter interval from diagnosis to first treatment and a shorter overall survival.

The BDA assay measures the dynamic changes in Bax protein level in CLL cells over time. Interestingly, there was no correlation between BDA and basal cellular Bax protein levels. This highlights the duality of protein regulation - namely, synthesis and degradation. The measurement of a Bax protein level at a single point in time must reflect the balance of these two processes - however, a high level of Bax could still be associated with high degradation activity if counterbalanced by increased synthesis. As the BDA assay uses post-nuclear extracts, the synthetic arm of Bax regulation has been eliminated and the assay provides an in vitro measure of the ubiquitin/proteasome degradation activity. Thus BDA is a dynamic indicator of intrinsic ubiquitin/proteasome 
activity in CLL cells and is a one-way 'output' (i.e., degradation) assay - without the synthetic 'input' arm. BDA could therefore be a more robust tool for prognostication and may partly explain why the literature contains contradictory reports on the prognostic value of Bax protein measurements in CLL. ${ }^{22-27}$

The BDA positive cases showed a marked accumulation of known poor prognostic features, shorter overall survival and time to first treatment as compared to the BDA negative group (Table 2 and Figures 3 and 4). Analysis of the cases with prognostically discordant results further supports the value of the BDA assay. For example, Bax instability (BDA positivity) conferred a poor prognosis in patients without other poor risk markers; stability of the Bax protein (BDA negativity) may have contributed to the longer than expected survival of patients who had other poor prognostic markers, suggesting persistent sensitivity of their cells in vivo to therapeutic agents.

CLL remains an incurable disease requiring repeated courses of treatment, with a decreasing success of therapies due to progressive bone marrow failure, immune suppression, infection and resistance to therapy. There is a need for therapies with novel mechanisms of action and reduced toxicities. We have shown that Bax instability plays a key role in the resistance of CLL cells and malignant B-cell lines to TRAIL-induced apoptosis (Liu et al, accompanying paper). Furthermore, we showed that it was possible to stabilize Bax with the proteasome inhibitor, Bortezomib, thereby sensitizing CLL cells to killing by TRAIL.

Bortezomib has shown anti-tumor activity in vivo in a number of cancer types, especially B-cell malignancies. ${ }^{28}$ In myeloma, both as a single agent and in combination 
with other treatments, Bortezomib has an established role in the therapeutic armamentarium. ${ }^{29,30}$ However, the efficacy of Bortezomib in patients with CLL has been disappointing. ${ }^{31}$ The in vitro sensitization of CLL cells to apoptosis by Bortezomib suggests that combination of proteasome inhibition with other therapies should be investigated in vivo. Recent studies suggest that synergy with Bortezomib and TRAIL (Liu et al, accompanying manuscript and 32), chemotherapeutic agents ${ }^{33}$, or Bortezomib and monoclonal anti-CD20 and anti-CD52 antibodies, ${ }^{34}$ may allow dose reduction of the individual agents, thereby minimizing their overall toxicities.

The BDA assay described here measures the intrinsic Bax instability of CLL cells and represents a new prognostic marker, with BDA positivity correlating with shorter survival and earlier treatment. There was a striking accumulation of established markers of poor prognosis in cases with Bax instability, suggesting that Bax instability may be a common 'final' pathway found in poor prognosis CLL and possibly other B-cell malignancies (this paper and Liu et al,). These findings will be extended to a larger, prospective study of the utility of the ubiquitin-mediated Bax degradation assay at diagnosis in uniformly treated patients, as well as with novel combinations, in CLL. 


\section{Authors' contributions}

1. SG Agrawal*: Designed and performed the research, wrote the paper, fund raising.

2. FT Liu*: performed research.

3. C Wiseman, S Shirali, H Liu, and D Lillington performed research.

4. D Syndercombe-Court analyzed data.

5. MQ Du, JG Gribben, AC Newland contributed design, project discussion, fund raising.

6. L Jia contributed design and perform the research, wrote part of the paper, fund raising.

*: SGA and FTL contributed equally to this work. 


\section{References}

1. Damle RN, Wasil T, Fais F, et al. Ig V gene mutation status and CD38 expression as novel prognostic indicators in chronic lymphocytic leukemia. Blood. 1999;94:1840-1847.

2. Hamblin TJ, Davis Z, Gardiner A, Oscier DG, Stevenson FK. Unmutated Ig V(H) genes are associated with a more aggressive form of chronic lymphocytic leukemia. Blood. 1999;94:1848-1854.

3. Crespo M, Bosch F, Villamor N, et al. ZAP-70 expression as a surrogate for immunoglobulin-variable-region mutations in chronic lymphocytic leukemia. $\mathrm{N}$ Engl J Med. 2003;348:1764-1775.

4. Orchard JA, Ibbotson RE, Davis Z, et al. ZAP-70 expression and prognosis in chronic lymphocytic leukaemia. Lancet. 2004;363:105-111.

5. Rassenti LZ, Huynh L, Toy TL, et al. ZAP-70 compared with immunoglobulin heavy-chain gene mutation status as a predictor of disease progression in chronic lymphocytic leukemia. N Engl J Med. 2004;351:893-901.

6. Dohner H, Stilgenbauer S, Benner A, et al. Genomic aberrations and survival in chronic lymphocytic leukemia. N Engl J Med. 2000;343:1910-1916.

7. Pettitt AR, Sherrington PD, Stewart G, Cawley JC, Taylor AM, Stankovic T. p53 dysfunction in B-cell chronic lymphocytic leukemia: inactivation of ATM as an alternative to TP53 mutation. Blood. 2001;98:814-822.

8. Castro JE, Prada CE, Loria O, et al. ZAP-70 is a novel conditional heat shock protein 90 (Hsp90) client: inhibition of Hsp90 leads to ZAP-70 degradation, apoptosis, and impaired signaling in chronic lymphocytic leukemia. Blood. 2005;106:2506-2512.

9. Chen L, Apgar J, Huynh L, et al. ZAP-70 directly enhances IgM signaling in chronic lymphocytic leukemia. Blood. 2005;105:2036-2041.

10. Deaglio S, Vaisitti T, Bergui L, et al. CD38 and CD100 lead a network of surface receptors relaying positive signals for B-CLL growth and survival. Blood. 2005;105:3042-3050. 
11. Deglesne PA, Chevallier N, Letestu R, et al. Survival response to B-cell receptor ligation is restricted to progressive chronic lymphocytic leukemia cells irrespective of Zap-70 expression. Cancer Res. 2006;66:7158-7166.

12. Scheffner M, Werness BA, Huibregtse JM, Levine AJ, Howley PM. The E6 oncoprotein encoded by human papillomavirus types 16 and 18 promotes the degradation of p53. Cell. 1990;63:1129-1136.

13. Breitschopf K, Zeiher AM, Dimmeler S. Ubiquitin-mediated degradation of the proapoptotic active form of bid. A functional consequence on apoptosis induction. $\mathrm{J}$ Biol Chem. 2000;275:21648-21652.

14. Chang YC, Lee YS, Tejima T, et al. mdm2 and bax, downstream mediators of the p53 response, are degraded by the ubiquitin-proteasome pathway. Cell Growth Differ. 1998;9:79-84.

15. Li B, Dou QP. Bax degradation by the ubiquitin/proteasome-dependent pathway: involvement in tumor survival and progression. Proc Natl Acad Sci USA. 2000;97:3850-3855.

16. Lotan R, Rotem A, Gonen H, et al. Regulation of the proapoptotic ARTS protein by ubiquitin-mediated degradation. J Biol Chem. 2005;280:25802-25810.

17. Perez-Galan P, Roue G, Villamor N, Montserrat E, Campo E, Colomer D. The proteasome inhibitor bortezomib induces apoptosis in mantle-cell lymphoma through generation of ROS and Noxa activation independent of p53 status. Blood. 2006; 107:257-264.

18. Miyashita T, Kitada S, Krajewski S, Horne WA, Delia D, Reed JC. Overexpression of the Bcl-2 protein increases the half-life of p21Bax. J Biol Chem. 1995;270:26049-26052.

19. McConkey DJ, Chandra J, Wright S, et al. Apoptosis sensitivity in chronic lymphocytic leukemia is determined by endogenous endonuclease content and relative expression of BCL-2 and BAX. J Immunol. 1996;156:2624-2630.

20. Wendt J, von Haefen C, Hemmati P, Belka C, Dorken B, Daniel PT. TRAIL sensitizes for ionizing irradiation-induced apoptosis through an entirely Baxdependent mitochondrial cell death pathway. Oncogene. 2005;24:4052-4064. 
21. Fecker LF, Geilen CC, Tchernev G, et al. Loss of proapoptotic Bcl-2-related multidomain proteins in primary melanomas is associated with poor prognosis. $\mathrm{J}$ Invest Dermatol. 2006;126:1366-1371.

22. Aguilar-Santelises M, Rottenberg ME, Lewin N, Mellstedt H, Jondal M. Bcl-2, Bax and p53 expression in B-CLL in relation to in vitro survival and clinical progression. Int J Cancer. 1996;69:114-149.

23. Molica S, Dattilo A, Giulino C, Levato D, Levato L. Increased bcl-2/bax ratio in Bcell chronic lymphocytic leukemia is associated with a progressive pattern of disease. Haematologica. 1998;83:1122-1124.

24. Bannerji R, Kitada S, Flinn IW, et al. Apoptotic-regulatory and complementprotecting protein expression in chronic lymphocytic leukemia: relationship to in vivo rituximab resistance. J Clin Oncol. 2003;21:1466-1471.

25. Starczynski J, Pepper C, Pratt G, et al. Common polymorphism G(-248)A in the promoter region of the bax gene results in significantly shorter survival in patients with chronic lymphocytic Leukemia once treatment is initiated. J Clin Oncol. 2005; 23:1514-1521.

26. Johnston JB, Daeninck P, Verburg L, et al. P53, MDM-2, BAX and BCL-2 and drug resistance in chronic lymphocytic leukemia. Leuk Lymphoma. 1997;26:435449.

27. Faderl S, Keating MJ, Do KA, et al. Expression profile of 11 proteins and their prognostic significance in patients with chronic lymphocytic leukemia (CLL). Leukemia. 2002;16:1045-1052.

28. Schwartz R, Davidson T. Pharmacology, pharmacokinetics, and practical applications of bortezomib. Oncology (Williston Park). 2004;18(14 Suppl 11):1421.

29. Richardson PG, Barlogie B, Berenson J, et al. A phase 2 study of bortezomib in relapsed, refractory myeloma. N Engl J Med. 2003 ;348:2609-2617.

30. Oakervee HE, Popat R, Curry N, et al. PAD combination therapy (PS341/bortezomib, doxorubicin and dexamethasone) for previously untreated patients with multiple myeloma. Bri J Haemat. 2005;129:755-762 
31. Faderl S, Rai K, Gribben J, et al. Phase II study of single-agent bortezomib for the treatment of patients with fludarabine-refractory B-cell chronic lymphocytic leukemia. Cancer. 2006;107:916-924.

32. Kabore AF, Sun J, Hu X, McCrea K, Johnston JB, Gibson SB. The TRAIL apoptotic pathway mediates proteasome inhibitor induced apoptosis in primary chronic lymphocytic leukemia cells. Apoptosis. 2006;11:1175-1193.

33. Duechler M, Linke A, Cebula B, et al. In vitro cytotoxic effect of proteasome inhibitor bortezomib in combination with purine nucleoside analogues on chronic lymphocytic leukaemia cells. Eur J Haematol. 2005;74:407-417.

34. Smolewski P, Duechler M, Linke A, et al. Additive cytotoxic effect of bortezomib in combination with anti-CD20 or anti-CD52 monoclonal antibodies on chronic lymphocytic leukemia cells. Leuk Res. 2006;30:1521-1529. 


\section{Figure legends}

Figure 1. Bax degradation activity in primary CLL cells.

The post-nuclear supernatants were extracted from PBL from a healthy donor and CLL cells and incubated with the ubiquitin and ATP regeneration system for up to 5 hours. 20 $\mu$ g proteins were loaded in each lane for SDS-PAGE. The Bax (clone 2D2) antibody was used in 1:1000 dilution and the $\beta$-actin antibody was used at 1:10,000 dilution. Numbers under each pairs of blots are ratios of Bax/ $\beta$-actin. Top panel shows results for a normal donor; lower 4 panels are cases of CLL.

Figure 2. Bax protein levels in different CLL patients.

Proteins were extracted from 15 different CLL samples using the lysis buffer. $20 \mu \mathrm{g}$ proteins were loaded each lane for SDS-PAGE. The Bax (clone 2D2) antibody was used in 1:1000 dilution and the $\beta$-actin antibody was used at 1:10,000 dilution. BDA positive $(+)$ and negative (-) cases are indicated above each lane.

Figure 3. Survival according to Bax degradation activity, VH, ZAP-70 and CD38 status: Bax instability confers a worse prognosis.

Kaplan-Meier plots of survival since diagnosis in patients classified according to a) BDA, b) VHmut, c) ZAP-70, and d) CD38 status, and also in patients with the combined markers e) $\mathrm{BDA}+$ and ZAP-70 +, and f) $\mathrm{BDA}+$, Binet stage $\mathrm{B}$ or $\mathrm{C}$, and CD38 +, compared with the remainder. Cox F test is used to compare the two groups in each plot. $\mathrm{n}=$ number of patients, $\mathrm{O}$ indicates patient is dead, + indicates patient is alive at time of analysis. 
Figure 4. Time to first treatment according to Bax degradation activity, VH, ZAP70 and CD38 status: Bax instability is associated with the need for early treatment.

Kaplan-Meier plots of time to first treatment since diagnosis in patients classified according to a) BDA, b) VHmut, c) ZAP-70, and d) CD38 status. Cox F test is used to compare the two groups in each plot. $\mathrm{n}=$ number of patients, $\mathrm{O}$ indicates time of first treatment, + indicates patient is untreated at time of analysis. 
Table 1: Association between Bax degradation activity, prognostic markers and clinical outcome

\begin{tabular}{|c|c|c|c|c|c|c|c|c|c|c|c|}
\hline \multirow{2}{*}{$\begin{array}{l}\text { Case } \\
\text { No. } \\
\text { CLL-1 }\end{array}$} & \multirow{2}{*}{$\begin{array}{c}\text { Bax } \\
\begin{array}{c}\text { degradation } \\
\text { activity }\end{array} \\
\text { Pos }\end{array}$} & \multirow{2}{*}{$\begin{array}{c}\text { Binet } \\
\text { stage }\end{array}$} & \multirow{2}{*}{$\begin{array}{c}\operatorname{IgV}_{H} \\
\text { mutation } \\
(\%) \\
0\end{array}$} & \multirow{2}{*}{$\begin{array}{c}\text { ZAP-70 } \\
+\end{array}$} & \multirow{2}{*}{$\begin{array}{c}\text { CD38 } \\
+\end{array}$} & \multirow{2}{*}{$\begin{array}{c}\begin{array}{c}\text { LDT } \\
\text { (months) }\end{array} \\
10\end{array}$} & \multirow{2}{*}{$\begin{array}{c}\text { Caryotype }^{1} \\
\text { (D13S319x1) }\end{array}$} & \multicolumn{2}{|c|}{$\begin{array}{l}\text { Treatment - } \\
\text { months from } \\
\text { diagnosis }\end{array}$} & \multicolumn{2}{|c|}{$\begin{array}{c}\text { Survival - } \\
\text { months from } \\
\text { diagnosis }\end{array}$} \\
\hline & & & & & & & & $\mathrm{Y}$ & 12 & alive & 63 \\
\hline CLL-2 & Pos & $\mathrm{B}$ & 0 & + & + & N/A & (ATMx1), (D13S319x1) & $\mathrm{Y}$ & 2 & alive & 81 \\
\hline CLL-3 & Pos & $\mathrm{C}$ & 0 & + & + & N/A & na & $\mathrm{Y}$ & 1 & dead & 30 \\
\hline CLL-4 & Pos & $\mathrm{A}$ & 3.6 & - & - & $>12$ & (D13S319x1) & $\mathrm{Y}$ & 36 & alive & 39 \\
\hline CLL-5 & Pos & A & na & - & - & $>12$ & (D13S319x1) & $\mathrm{N}$ & & alive & 135 \\
\hline CLL-6 & Pos & $\mathrm{A}$ & 0 & + & - & N/A & (D13S319x1), (p53x1) & $\mathrm{Y}$ & 2 & dead & 126 \\
\hline CLL-7 & Pos & A & 1 & + & - & 6 & (D13S319x1) & $\mathrm{N}$ & & dead & 36 \\
\hline CLL-8 & Pos & $\mathrm{C}$ & 1.7 & - & - & N/A & $+12,+19$ & $\mathrm{Y}$ & 1 & dead & 210 \\
\hline CLL-9 & Pos & $\mathrm{B}$ & 3.6 & + & + & 6 & Normal & $\mathrm{Y}$ & 10 & alive & 33 \\
\hline CLL-10 & Pos & A & 7.6 & + & + & 4 & $\begin{array}{c}\text { (D13S319x1)/ (D13S319x0) } \\
\text { (CEP12x3) }\end{array}$ & $\mathrm{N}$ & & alive & 63 \\
\hline CLL-11 & Pos & $\mathrm{A}$ & na & + & - & $>12$ & $\operatorname{del}(11)(\mathrm{q} 22 \mathrm{q} 23)$ & $\mathrm{Y}$ & 39 & alive & 69 \\
\hline CLL-12 & Pos & $\mathrm{B}$ & 2.9 & + & + & 7 & Complex ${ }^{\#}$ & $\mathrm{Y}$ & 1 & dead & 18 \\
\hline CLL-13 & Pos & $\mathrm{A}$ & 12.5 & - & + & $>12$ & $(\mathrm{D} 13 \mathrm{S319x1}) /(\mathrm{D} 13 \mathrm{S319x0})$ & $\mathrm{Y}$ & 108 & alive & 123 \\
\hline CLL-14 & Pos & $\mathrm{A}$ & 0 & + & + & $>12$ & (ATMx1) & $\mathrm{Y}$ & 54 & dead & 84 \\
\hline CLL-15 & Pos & A & 0.7 & + & + & $>12$ & (D13S319x1)/ (D13S319x0) & $\mathrm{N}$ & & alive & 60 \\
\hline CLL-16 & Pos & $\mathrm{B}$ & na & - & + & N/A & Complex* & $\mathrm{Y}$ & 0.25 & dead & 10 \\
\hline CLL-17 & Pos & A & 8.7 & - & + & $>12$ & $\begin{array}{c}\text { (D13S319x1)/ (D13S319x0) } \\
\text { (CEP12x3) }\end{array}$ & $\mathrm{Y}$ & 72 & alive & 111 \\
\hline CLL-18 & Pos & $\mathrm{B}$ & 0 & + & + & 6 & Normal & $\mathrm{Y}$ & 12 & dead & 144 \\
\hline CLL-19 & Pos & A & na & - & - & $>12$ & $\begin{array}{c}\text { (D13S319x1)/ (D13S319x0) } \\
(\mathrm{p} 53 x 1)\end{array}$ & $\mathrm{N}$ & & alive & 41 \\
\hline CLL-20 & Pos & $\mathrm{C}$ & na & - & + & $>12$ & Normal & $\mathrm{Y}$ & 9 & dead & 31 \\
\hline CLL-21 & Pos & A & na & - & - & $>12$ & Normal & $\mathrm{N}$ & & alive & 12 \\
\hline CLL-22 & Pos & A & 5.7 & - & + & N/A & (D13S319x1) & $\mathrm{Y}$ & 4 & alive & 75 \\
\hline CLL-23 & Pos & $\mathrm{B}$ & 4.0 & - & - & 7 & (D13S319x0) & $\mathrm{Y}$ & 12 & alive & 15 \\
\hline CLL-34 & Pos & B & 6.0 & - & - & N/A & $\begin{array}{c}\text { (D13S319x1)/ (D13S319x0) } \\
\text { (CEP12x3)/ (IGHsp) }\end{array}$ & $\mathrm{Y}$ & 1 & alive & 11 \\
\hline CLL-37 & Pos & $\mathrm{A}$ & 9.4 & - & - & $>12$ & (D13S319x1) & $\mathrm{Y}$ & 36 & alive & 43 \\
\hline CLL-38 & Pos & $A$ & 8.0 & - & + & 6 & (D13S319x1)/(D13S319x0) & $\mathrm{N}$ & & alive & 27 \\
\hline CLL-24 & Neg & A & 10 & - & - & $>12$ & (D13S319x1)/ (D13S319x0) & $\mathrm{N}$ & & alive & 75 \\
\hline CLL-25 & Neg & A & 0 & + & + & N/A & (CEP12x3) & $\mathrm{Y}$ & 4 & dead & 144 \\
\hline CLL-26 & Neg & A & 15.9 & - & - & $>12$ & Normal & $\mathrm{Y}$ & 180 & alive & 195 \\
\hline CLL-27 & Neg & A & 8.8 & - & - & $>12$ & (D13S319x1) & $\mathrm{N}$ & & alive & 63 \\
\hline CLL-28 & Neg & A & na & - & - & $>12$ & (D13S319x0) & $\mathrm{N}$ & & alive & 135 \\
\hline CLL-29 & Neg & $\mathrm{A}$ & 7.4 & - & - & $>12$ & (D13S319x1)/ (D13S319x0) & $\mathrm{Y}$ & 156 & alive & 171 \\
\hline CLL-30 & Neg & A & na & na & + & $>12$ & $\begin{array}{c}\mathrm{t}(6 ; 13)(\mathrm{p} 21 ; \mathrm{q} 14), \text { add(14)(q32)/ } \\
(\mathrm{D} 13 S 319 \mathrm{x} 1)\end{array}$ & $\mathrm{Y}$ & 90 & alive & 123 \\
\hline CLL-31 & Neg & A & na & - & - & $>12$ & (D13S319x1)/ (D13S319x0) & $\mathrm{N}$ & & alive & 123 \\
\hline
\end{tabular}




\begin{tabular}{|c|c|c|c|c|c|c|c|c|c|c|c|}
\hline CLL-32 & Neg & $\mathrm{A}$ & na & - & - & 3 & (D13S319x1)/ (D13S319x0) & $\mathrm{Y}$ & 2 & alive & 147 \\
\hline CLL-33 & Neg & A & 1.2 & - & - & $>12$ & (D13S319x1)/ (D13S319x0) & $\mathrm{N}$ & & alive & 123 \\
\hline CLL-35 & Neg & $\mathrm{B}$ & 0 & + & + & 10 & Normal & $\mathrm{N}$ & & alive & 15 \\
\hline CLL-36 & Neg & A & 1.0 & + & - & $>12$ & $\begin{array}{l}\text { +12, del(14)(q13q32)/ } \\
\text { (CEP12x3) }\end{array}$ & $\mathrm{Y}$ & 25 & alive & 66 \\
\hline CLL-39 & Neg & $\mathrm{A}$ & na & - & - & $>12$ & Normal & $\mathrm{N}$ & & alive & 70 \\
\hline CLL-40 & Neg & A & 5.0 & - & - & 9 & (D13S319x1) & $\mathrm{Y}$ & 34 & alive & 45 \\
\hline
\end{tabular}

Binet clinical stage at diagnosis; $\operatorname{IgV}_{\mathrm{H}}$ : using < $2 \%$ as the threshold for unmut: unmutated; mut: mutated; LDT: lymphocyte doubling time; na: not available; N/A: not applicable (treatment started before LDT assessable); N: no; Y: yes; Pos: positive; Neg: negative.

1: D13S319 = probe for 13q14, ATM = probe for 11q22, CEP12 = chromosome 12 enumeration probe, $\mathrm{IGH} \backslash=$ probe for $14 \mathrm{q} 32$, $\mathrm{p} 53$ = probe for $17 \mathrm{p} 13$; $\mathrm{x} 1=$ monoallelic deletion, $\mathrm{x} 0$ = biallelic deletion; Normal = all FISH probes were present in two copies; Complex = more than 3 cytogenetic abnormalities;

\#: complex includes loss of 9p, partial trisomy 12q, loss of 17p.

*: complex includes del (13) (q1q2) and 14q32 rearrangement. 
Table 2: Association between Bax degradation activity, established prognostic markers and clinical outcome

\begin{tabular}{|c|c|c|c|c|c|c|c|c|}
\hline $\begin{array}{c}\text { Bax degradation } \\
\text { activity }\end{array}$ & $\begin{array}{l}\text { Binet stage } \\
\text { A / B or C }\end{array}$ & $\begin{array}{c}\text { IgV } V_{\mathrm{H}} \\
\text { mut / unmut }\end{array}$ & $\begin{array}{c}\text { ZAP-70 } \\
-/+\end{array}$ & $\begin{array}{l}\text { CD38 } \\
-/+\end{array}$ & $\begin{array}{c}\text { LDT } \\
>12 /<12\end{array}$ & $\begin{array}{c}\text { Caryotype } \\
\text { other / 11q-, 17p- }\end{array}$ & $\begin{array}{c}\text { Treatment } \\
\text { no / yes }\end{array}$ & $\begin{array}{c}\text { Survival } \\
\text { alive / dead }\end{array}$ \\
\hline Positive $(n=26)$ & $16 / 10$ & $11 / 9$ & $14 / 12$ & $11 / 15$ & $11 / 15$ & $20 / 6$ & $7 / 19$ & $17 / 9$ \\
\hline Negative $(\mathrm{n}=14)$ & $13 / 1$ & $5 / 4$ & $10 / 3$ & $11 / 3$ & $10 / 4$ & $14 / 0$ & $7 / 7$ & $13 / 1$ \\
\hline $\mathrm{P}$ value & $0.06^{*}$ & $0.65 *$ & 0.29 & 0.06 & 0.15 & $0.07 *$ & $0.18 *$ & $0.07 *$ \\
\hline
\end{tabular}

LDT: lymphocyte doubling time ( $<12$ includes cases where treatment was started before LDT could be assessed); Binet clinical stage at diagnosis; IgV $\mathrm{H}_{\mathrm{H}}$ : using $<2 \%$ as the threshold for unmut: unmutated; mut: mutated; 11q-: 11q22 deletion by FISH or G-banding; 17p-: 17p13 deletion by FISH or G-banding.

*: Tests were 2-sided Fisher's exact test; otherwise p values were obtained using Chi-square with Yate’s correction. 
Time $\begin{array}{lllll}0 & 1 & 3 & 5 & \text { hrs }\end{array}$
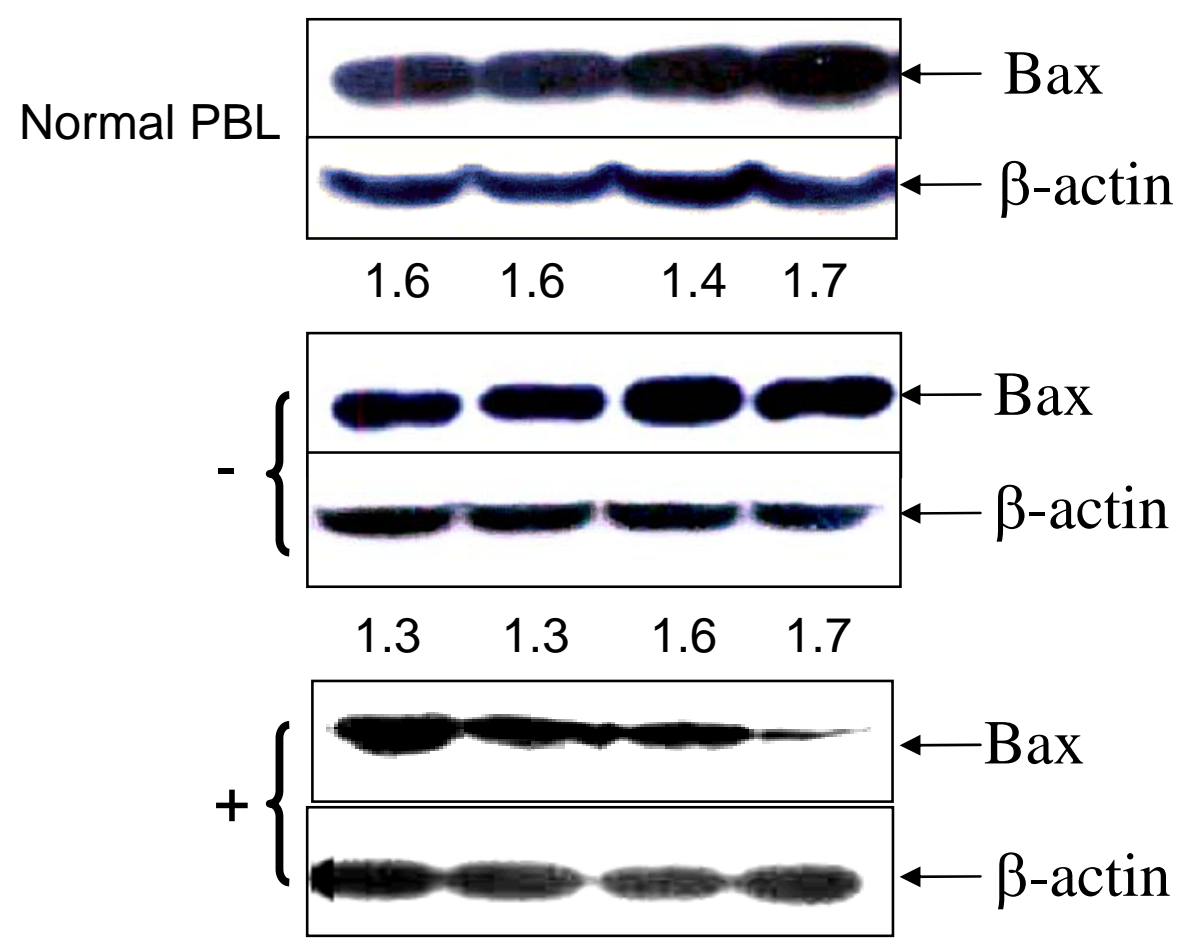

$\begin{array}{llll}0.9 & 1 & 0.7 & 0.2\end{array}$
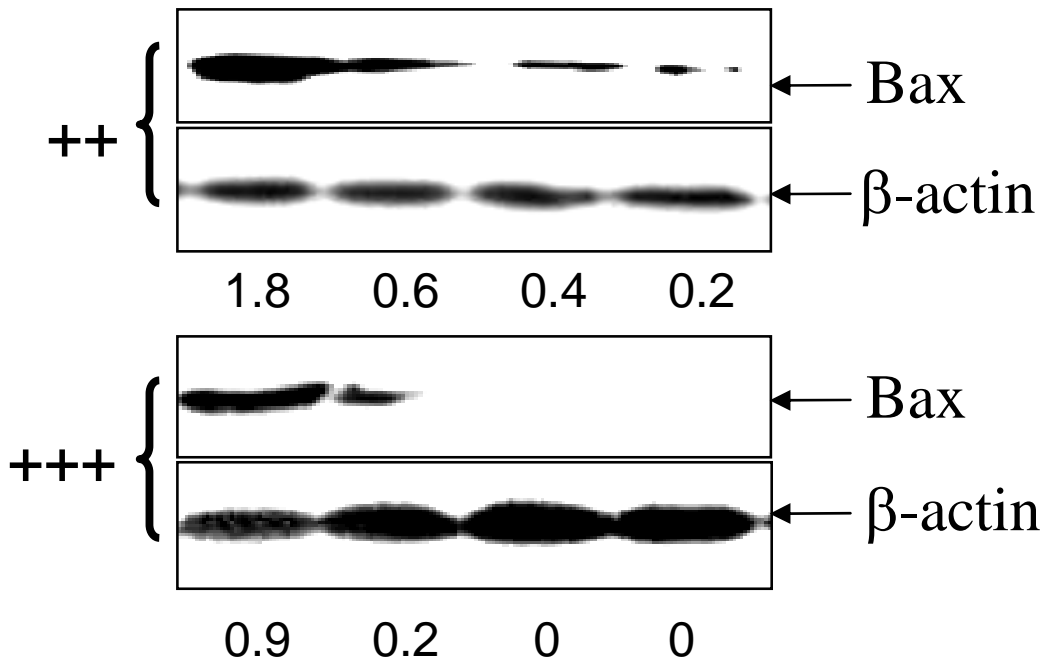

Figure 1: Variable Bax degradation in CLL cells 


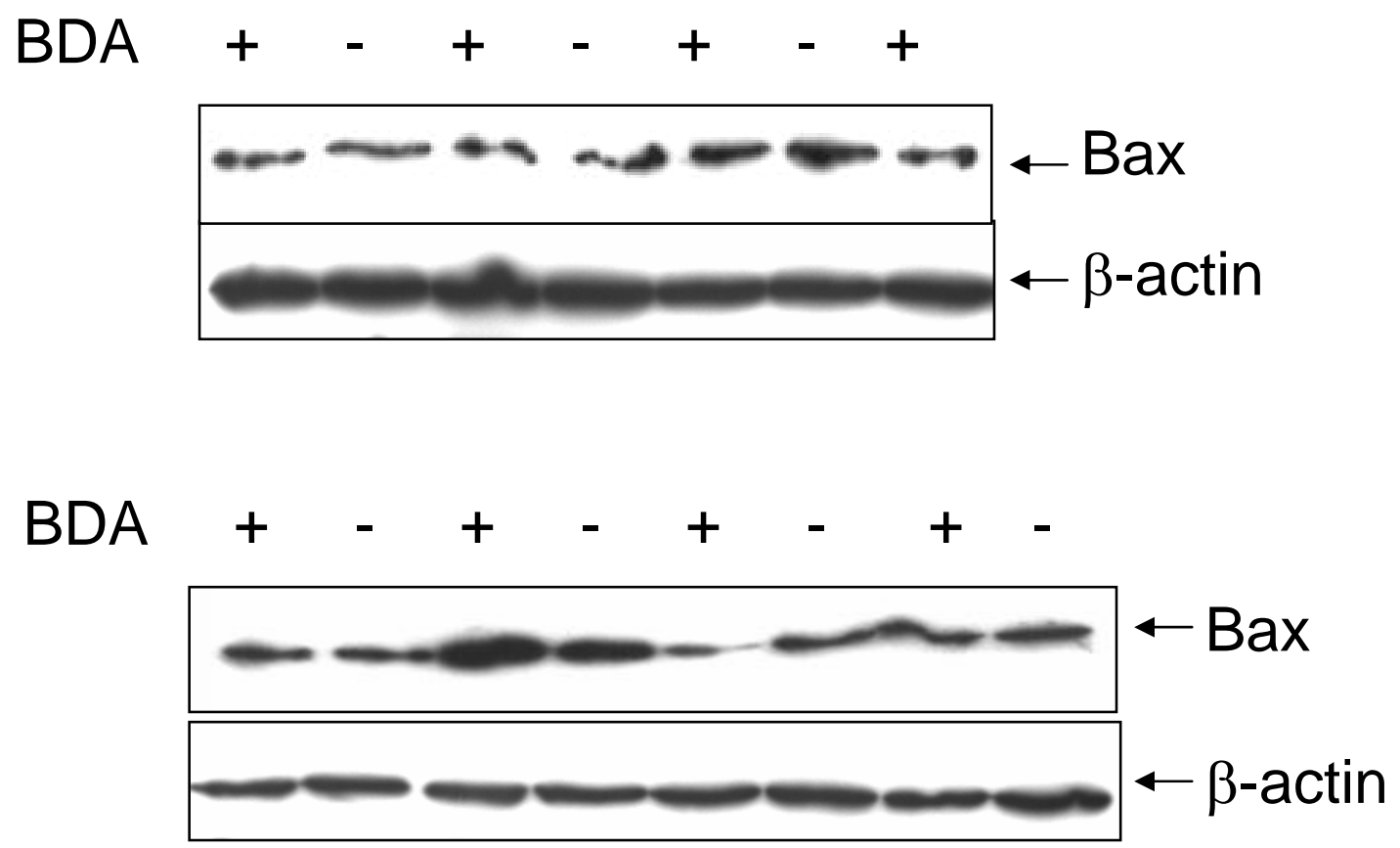

Figure 2. Bax expression in CLL 
a
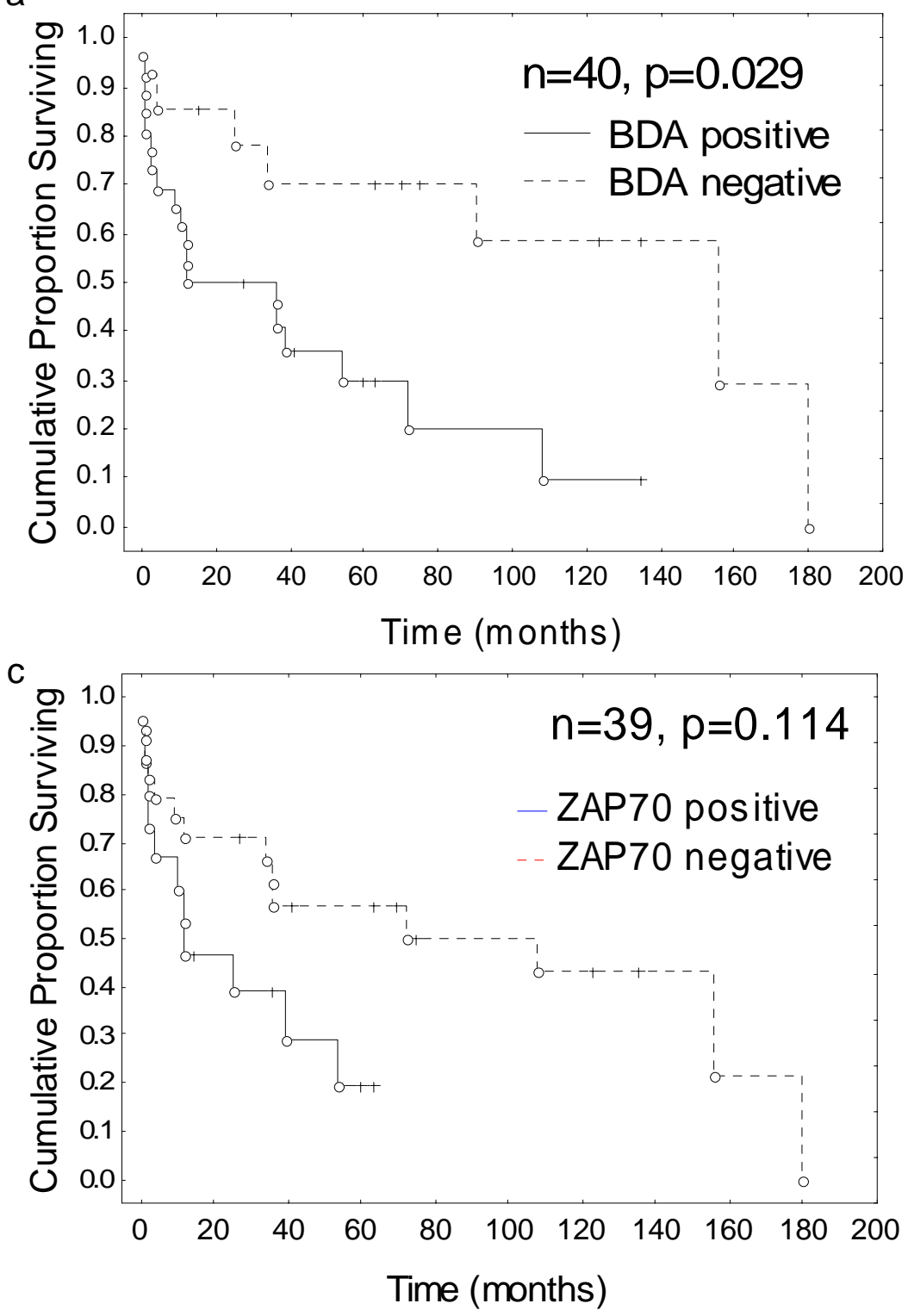

b

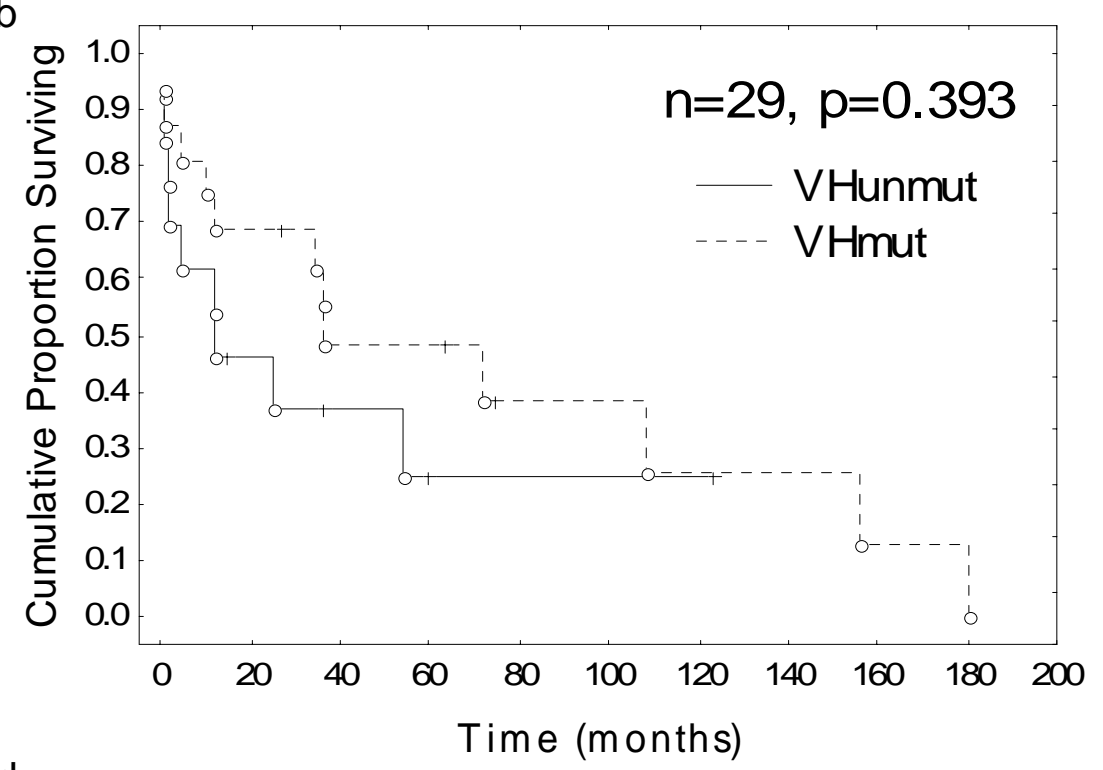

$d$

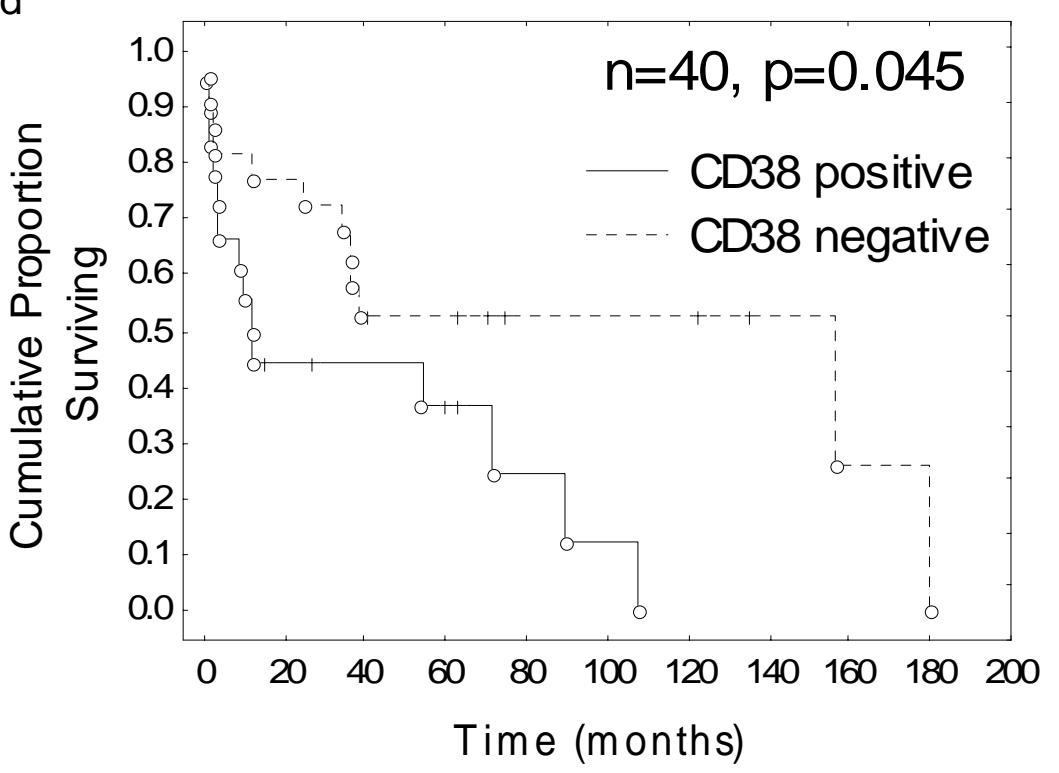

Figure 3. Survival according to Bax degradation activity, VH, ZAP70 and CD38 status: Bax instability confers a worse prognosis 

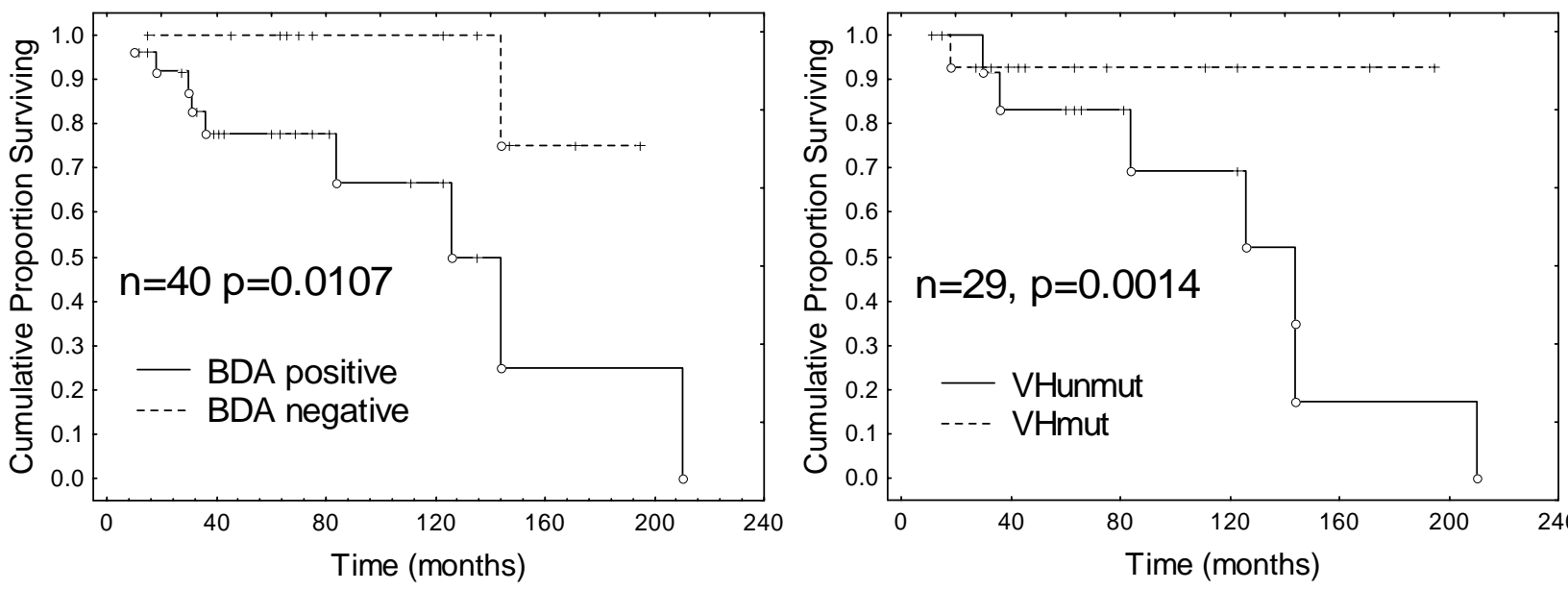

e

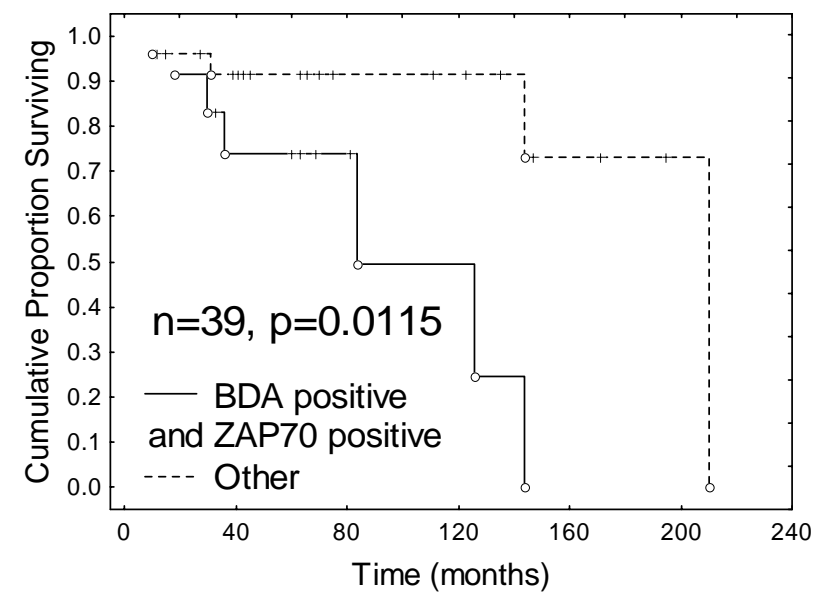

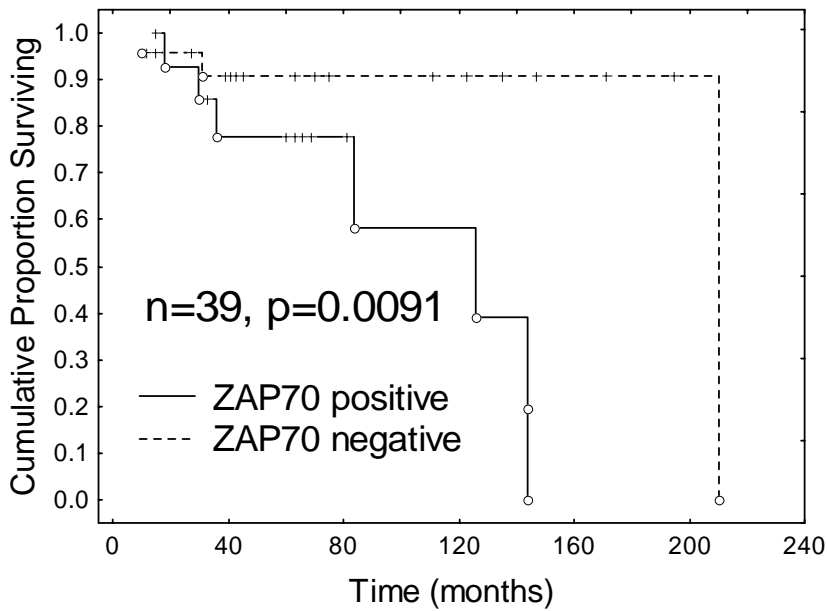

f

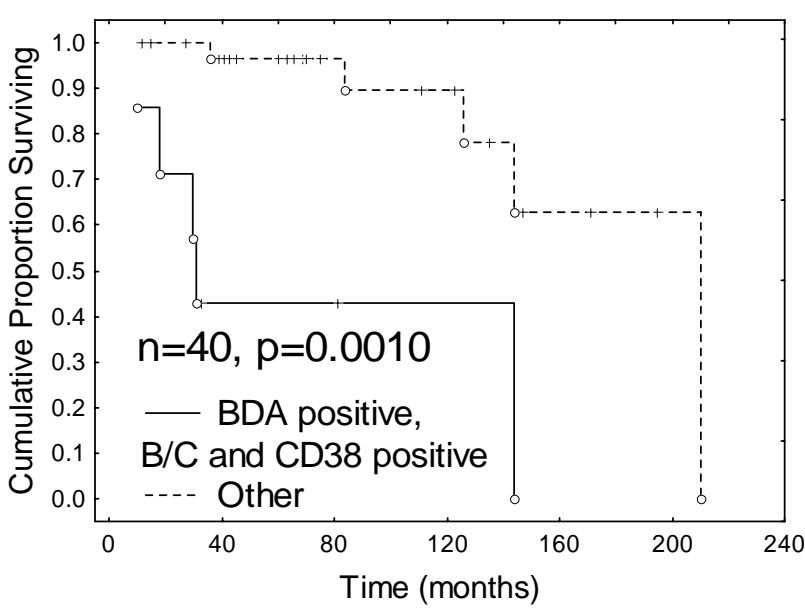

Figure 4. Time to first treatment according to Bax degradation activity, VH, ZAP70 and CD38 status: early treatment is associated with Bax instability 